\title{
$\mathrm{KCl}$ 수용액에서 CPC/TX-100 혼합계면활섬제의 미셀화에 대한 열역학적 연구
}

\author{
김염철 ${ }^{+}$- 이병환* \\ 대구퐝역시 보건환경연구원 \\ 한국기술교육대학교 응용화학공학과 \\ (2005. 7.22 칩수)
}

\section{Thermodynamics on the Micellization of CPC/TX-100 Mixed Surfactant System in Aqueous Solutions of KCl}

\author{
Yung-Cheol Kim ${ }^{\dagger}$ and Byung-Hwan Lee* \\ "Health and Emironmental Researh Institute, Taegu 706-090, Korea \\ Depariment of the Applied Chemical Engineening, Konea Lniversin of Technology \& Estacation, \\ Chonan 333-860, Korea \\ (Received July 22. 2005)
}

요 약. $\mathrm{KCl}$ 수홍액에서 양이온 계면활성제인 Cetylpyridinium chloride(CPC)와 비이혼 계면 활성제인 Triton $\mathrm{X}-100(\mathrm{TX}-100)$ 의 혼합계면활성제의 임계미셀농도 $(\mathrm{CMC})$ 를 온도 $15^{\circ} \mathrm{C}$ 에 서 $35^{\circ} \mathrm{C}$ 까지 UV 홉광도법으로 측정하 였나. 측정된 $\mathrm{CMC}$ 값의 온도에 따른 변화로부터 여러 가지 열역학 함수값 $\left(\Delta \mathrm{G}_{\mathrm{m},}^{*} \Delta \mathrm{H}_{\mathrm{m}}^{*}\right.$ 및 $\left.\Delta \mathrm{S}_{\mathrm{m}}^{\circ}\right)$ 을 계,산하 고 분석하였다. 그 결과, 측정범위 내에서 $\triangle \mathrm{G}_{\mathrm{m}}^{\mathrm{m}}$ 은 모누 음의 값을 그러고 $\Delta \mathrm{S}_{\mathrm{m}}^{\circ}$ 값은 모누 양의 값을 나타내 었나. 그러나 $\triangle \mathrm{H}^{\mathrm{n}}$ 은 측정한 온도에 따라 양 혹은 음의 값을 나타내었다.

주제어: $\mathrm{CPC}, \mathrm{TX}-100$, 임계미셀농도, 반대이온 결합상수, 눙구조 온도

ABSTRACT. The critical micelle concentration (CMC) of the mixed surfactant system of Cetylpyridinium chloride (CPC) with Triton $\mathrm{X}-100$ (TX-100) in aqueous solutions of $\mathrm{KCl}$ were determitned by using the UV absortance method from $15^{\circ} \mathrm{C}$ to $35^{\circ} \mathrm{C}$. Thermodynamic parameters $\left(\Delta \mathrm{G}_{\mathrm{m}}^{\circ}, \triangle \mathrm{H}_{\mathrm{m},}^{\circ}\right.$ and $\left.\triangle \mathrm{S}_{\mathrm{m}}^{\circ}\right)$, associated with the micelle formation of CPCITX-100 mixed surfactant system, have been estimated from the temperature dependence of CMC values. The calculated values of $\triangle G_{\mathrm{m}}^{\circ}$ are all negative but the values of $\triangle S_{\mathrm{m}}^{\prime}$ are positive in the whole measured temperature region. On the other hand. the values of $\Delta \mathrm{H}_{\mathrm{m}}^{\prime \prime}$ are positive or negative. depending on the measured temperature.

Keywords: CPC, TX-100, Critical micelle Concentration, Counter Ion Binding Constant, Iso-Structural Temperature

\section{서 론}

수흠액에서 계면활성제분자늘의 미셀화 현상을 설 명하기 위하여 여러 가지 이론과 도델들이 개발되고 있다. ${ }^{1 \cdots 3}$ 특히 임계미셀농도(CMC)의 온도의존성으로. 부터 여러 가지 열역학 함수값들을 계.산하고 분석함 으로써 계면활성제분자들의 미셀화 현상을 열역학적
으로 설명하기 위한 이론늘이 많이 개발되고 있나. 지 급까지 알려진 바에 외하면 온도의 증가에 마라 $\mathrm{CMC}$ 값은 갑소하다가 증가하는 경항을 보이며, 실온근처 에서 최소값을 나타낸다.+" 은도에 따른 CMC의 이러 한 변화로부터 $\triangle \mathrm{G}_{\mathrm{m}}^{\circ}$ 은 식 (1)에 외하여 그리고 $\triangle \mathrm{H}_{\mathrm{m}}^{\mathrm{\nu}}$ 의 값은 식 (2)에 외하여 례산할 수 있었다. ${ }^{23}$ 여기서 $\mathrm{R}$ 과 $\mathrm{T}$ 는 각각 이상기체상수와 절대온도를 나타내며. 
$\beta$ 는 미셀 상에서 반대이온의 결합상수를 나타낸나. 한편 Mesa와 Muller 둥은 최소값의 임계미셀농도

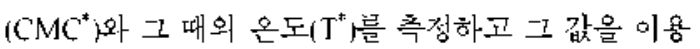
하여 열역학 함수값들을 계.산할 수 있는 이론을 개발 하기도 하였다. ${ }^{260}$ 일반적으로 계면활성제의 미셀화 에 대한 $\wedge \mathrm{G}_{\mathrm{m}}^{\circ}$ 값은 대부분 음의 값을 나타네며, 이 것은 $\Delta \mathrm{H}^{\nu}$ 과 $\triangle \mathrm{S}^{\circ}$ 의 누 인자들이 상호보완적으로 기여함으로써 나타나는 현상이다. ${ }^{i s}$

$$
\begin{gathered}
\Delta G_{m}^{o}=(1+\beta) R T \ln C M C \\
\Delta H_{m}^{\prime}=-(1+\beta) R T^{2} \frac{d(\ln C M C)}{d T}
\end{gathered}
$$

지금까.지는 단일 성분 계면활성제의 미셀화에 대하 여 열역학적 연구가 활발히 진행되어 왔지만 혼합계 면활섬제의 미셀화에 대한 연구는 많지 않았나.+1․ㅣ 섬유, 염색, 윤할유, 농약, 게인트 등의 산업현 장이나 가정용 세제에서는 생산에서의 어려움 때문에 단일 성분의 계면할성제보다는 혼합계면활성제가 많이 차 횽되고 있으므로 혼합계면활성제에 대한 연구가 풜 요하다. 일반적으로 누 종류의 계면활성제를 혼합하 면 단일 성분이 나타낼 수 없는 특이한 현상들을 나 타-낸다. 마라서 본 연구에 서는 양이온 계면활성제인 Cetylpyridinium chloride(CPC: $\mathrm{C}_{10} \mathrm{H}_{33} \mathrm{~N}^{+} \mathrm{C}_{5} \mathrm{H}_{5} \mathrm{Cl}^{-}$)와 Polyoxyethylene 계열의 비이온 계면활성제인 Triton $\mathrm{X}-100 \mathrm{TX}-100, \mathrm{C}_{8} \mathrm{H}_{1}, \mathrm{C}_{\mathrm{r}} \mathrm{H}_{4}\left(\mathrm{O} \mathrm{CC}_{2} \mathrm{H}_{4}\right)_{10} \mathrm{OH}$ 의 흔합계 면활 성제를 선정하였나. 그리고 이 혼합계면활성제에서 $\mathrm{CPC}$ 의 겉보기몰분율 $\left(\alpha_{1}\right)$ 을 0.9 로 고정하였으며. 이것 은 CPC/TX-100 혼합계면활성제 중에서 $\alpha_{1}$ 이 0.9 인 대 온도에 따른 CMC의 변화가 가장 크게 나타났기 때문이다. 이 혼합계면활성제의 열역학적 연구를 위 하여 온도를 변화시키면서 $\mathrm{CMC}$ 를 측정하였으며 또 한 미셀 상에서 반대이온의 결합상수값( $(3)$ 를 계.산하 기 위하여 염 $(\mathrm{KCl})$ 의 농도름 변화시키면서 $\mathrm{CMC}$ 륵 측 칭하였다.

\section{실 험}

계면활성제인 CPC와 TX-100은 순도가 $98^{\circ} \%$ 이상 인 Aldrich 제품을 더 이상 정제하지 않고 바로 사용 하였으며. 측정기기와 실헙방법은 전편의 논문에서와 같은 방법을 이용하였다. 륵 용액의 흡광도를 측정 하기 위하여 KONTRON사의 UV 분광광도계를 사용
하였으며. 횽액에서 계면활성제의 농도에 따른 홉광 도외 변화로부터 $\mathrm{CMC}$ 를 측칭하였다. 왕액제조를 위 하여 우선 KC의 저장용액을 만들었으며, 이 용액을 이왕하여 농도가 각각 $0.01 \mathrm{M}$ 인 CPC와 TX-100의 저 장용액을 만들었나. 그런 후. 이 횽액늘을 일정한 비 율로 마이크로피펫으로 춰하여 혼합함으로써 혼합계 면활성제의 저장용액을 만들었다. 이 저잠용액을 앞 에서 반든 $\mathrm{KCl}$ 저잠용액으로 계속 묽힘으로써 계면 활성제의 전체농도가 각기 다른 용액 12개를 제조하 였다. 이와 같이 저장용액을 만들어 계촉 붉힘으로써 12 개외 왕액에서 도두 두 성분의 농도비와 $\mathrm{KCl}$ 의 농 도를 일정하게 유지할 수 있었나. 제조한 12 개 횽액 의 홉광도름 측정하여 계면 활성제의 전체농도에 대 하여 도시하면 기을기가 서로 다른 누 직선이 교차하 게 된다. ${ }^{3}$ Shanks와 Zana 둥에 의하면 이 누 지선의 교점은 바로 (MMC를 나타네므로 두 직선의 교섬으로 부터 $\mathrm{CMC}$ 를 측정하였다. ${ }^{14.1^{1}}$ 열역학적 연구를 위하여 $15^{\circ} \mathrm{C}$ 에서 $45^{\circ} \mathrm{C}$ 까지 $10^{\circ} \mathrm{C}$ 간격으로 쯕징하였으며 또 한 $\mathrm{KCl}$ 의 놈도는 $0 \mathrm{mM}$ 에서 $8 \mathrm{mM}$ 까지 $2 \mathrm{mM}$ 간격으 로 변화시키면서 측정하였다.

\section{곁과 및 고찰}

순수 눌 및 $\mathrm{KCl}$ 을 함유하는 수용액에서 CPC/TX100 혼합계면할성제 $\left(\alpha_{1}=0.9\right)$ 의 미셀화에 대하여 측징 한 CMC 값을 Table 1에 나타내없으며, Fig. 1에는 온 도변화에 따른 $\mathrm{CMC}$ 값의 변화를 도시하였다. 여기 서 할 수 있듯이 CPC/TX-100 혼합계면활성제의 $\mathrm{CMC}$ 는 은도외 증기에 따라 감소하다가 증가하는 경항을 보였으며. $298 \mathrm{~K}$ 근처에서 최소값을 보이고 있나. 일 반적으로 $\ln \mathrm{CMC}$ 값은 온도의 2차함수로서 식 (3)과 같이 나타낼 수 있으며, ${ }^{1 ;}$ i 여기서 $\mathrm{CMC}$ 는 보통 돌분 율 척도로 나타낸나. 또한 상수 $a$ 와 $b$ 는 각각 $\mathrm{K}^{-2}$ 과 $\mathrm{K}^{-1}$ 의 단위를 가지며 상수 $c$ 는 단위를 갖지 않는나. Table 1에 있는 각 $\mathrm{KCl}$ 왕액에서 측칭한 $\mathrm{CMC}$ 값을 식 (3)에 대입하여 최소자충법으로 $a, b$ 및 $c$ 를 구하 였으며, 그 결과를 RMSD(root mean square deviation) 값과 함께 Table 2에 나타내었나. 또한 각 횽액에서 최소값의 임계미셀농도(CMC')와 그 때의 온도 $\left(\mathrm{T}^{*}\right)$ 및 자유-에너지의 변화값 $\left(\mathrm{C}_{\mathrm{O}}^{*}\right)$ 를 회소자승법으로 계.산 하여 Table 2에 함께 나타네었다.+is 여기서 할 수 있 듯이 순수 불 및 모든 $\mathrm{KCl}$ 용액에서 T는 모두 $298 \mathrm{~K}$ 


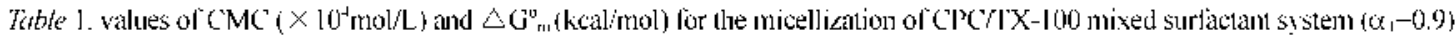
in aqueous solutions of $\mathrm{KCI}$ at various temperatures

\begin{tabular}{|c|c|c|c|c|c|c|c|c|}
\hline \multirow{2}{*}{$\begin{array}{l}\operatorname{lcmp}(\mathrm{K}) \\
\mathrm{K} \operatorname{Cl}(\mathrm{mM})\end{array}$} & \multicolumn{2}{|c|}{288} & \multicolumn{2}{|c|}{298} & \multicolumn{2}{|c|}{308} & \multicolumn{2}{|c|}{318} \\
\hline & $\mathrm{CMC}$ & $\wedge G^{\prime \prime}$ & CMC & $\curvearrowright \mathrm{G}^{\prime \prime}$ & $\mathrm{CMC}$ & $\wedge \mathrm{O}_{\mathrm{m}}^{\prime \prime}$ & $\mathrm{CMC}$ & $\triangle G^{\prime \prime}$ \\
\hline 0 & 7.26 & -6.33 & 6.97 & -6.54 & 7.26 & -6.72 & 7.66 & -6.85 \\
\hline 2 & 4.35 & -6.78 & 4.17 & -7.00 & 4.41 & -7.19 & 4.54 & -7.34 \\
\hline 4 & 2.97 & -7.11 & 2.93 & -7.33 & 3.05 & -7.53 & 3.41 & -7.62 \\
\hline 6 & 2.35 & -7.32 & 2.23 & -7.57 & 2.36 & -7.77 & 2.60 & -7.88 \\
\hline 8 & 2.05 & -7.44 & 2.01 & -7.66 & 2.10 & -7.88 & 2.31 & -7.99 \\
\hline
\end{tabular}

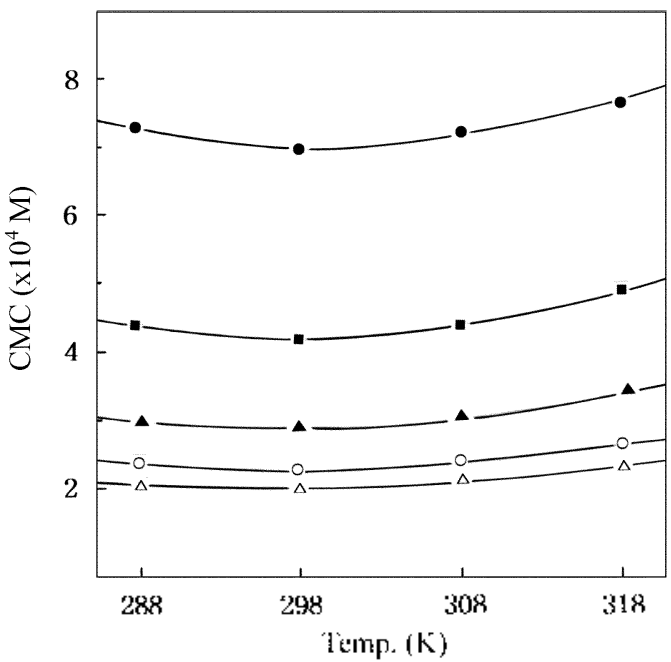

fig. I. Plots of CMC versus temperature for the micellization of CPC/TX-100 mixed surfactant system $\left(x_{1}=0.9\right)$ in

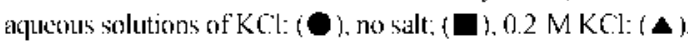

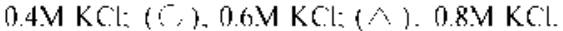

근처의 값은 나타내었으며. $\mathrm{CMC}^{*}$ 와 $\triangle \mathrm{G}^{*}$ 는 노두 $\mathrm{KCl}$

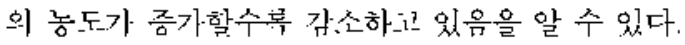

$$
\ln (\omega)=a T^{2}+b \%+c
$$

Toble 1에 나타낸 CMC 값은 KCl의 궁도가 충가할 수록 갑소하는 겅향을 보었으며. 일반적으로 Shinoda 등에 의하면 $\operatorname{lnCMC}$ 는 $\ln (\mathrm{CMC}+[\mathrm{KCl}])$ 에 대하-여 식

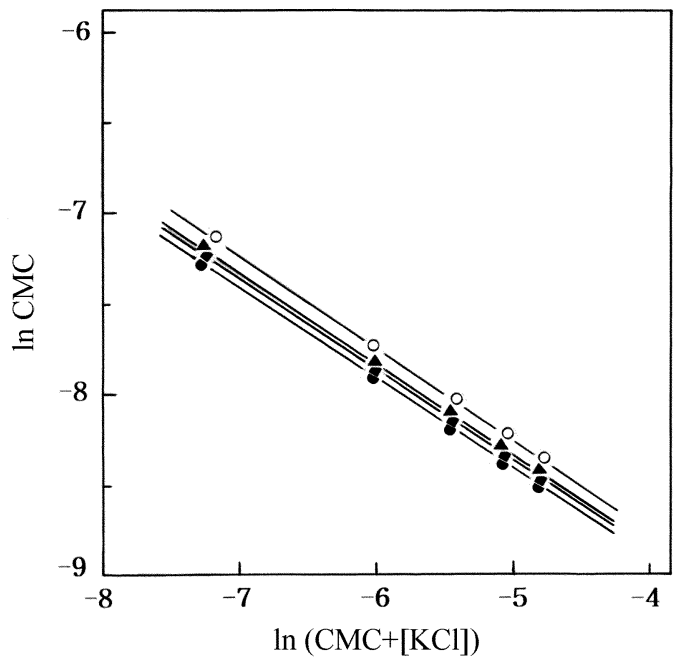

Fig. 2. Plots of $\operatorname{lnC} \mathrm{CHC}$ versus In(C.MC $\mid \mathrm{KCl})$ for the micellization of CPC/TX-100 mixed surfactant system $(0,-0.9)$ at several temperatures: $(\bullet), 288 \mathrm{~K}:(\boldsymbol{\square}) .298 \mathrm{~K} .(\boldsymbol{\Delta})$. $308 \mathrm{~K}:\left({ }^{\circ}\right), 318 \mathrm{~K}$.

(4)와 같이 비레하는 것으로 알려겼다. ${ }^{1 \times}$ Table 1의 쯕 정한 $\mathrm{CMC}$ 값을 식 (4)에 석용하여 도시한 결과는 $\mathrm{Fig}$, 2에 나타내었나. 각 온도에서 최소자승법을 적용 하여 직선의 기열기 $(A)$ 와 절편 $(B)$ 을 계산하었나. 그 견과 모든 온도에시 기을-기는 모누 -0.52의 농일한 값 을 나타내었으며. 전편은 -11 근처의 값으로서 측싱 한 온도에 마라 약간씩 달랐다. 여기서 식선의 기울

Table 2. Derived least squire partimeters (frum equation 3), dhemodynamic parameters, and root mein square deviation (RMSD) for the micellization of $\mathrm{CP}\left(/ / \mathrm{X}-100\right.$ mised surfactant system $\left(\alpha_{1}-0.9\right)$ in aqueous solutions of $\mathrm{KC}$.

\begin{tabular}{cccccccc}
\hline \hline $\mathrm{KCl}(\mathrm{m} \cdot \mathrm{M})$ & $a\left(10^{-4} \mathrm{~K}^{-1}\right)$ & $b\left(\mathrm{~K}^{-1}\right)$ & $c$ & $\mathrm{~T}^{*}(\mathrm{~K})$ & $\left(\mathrm{MC}^{* *}\left(10^{+} \mathrm{M}\right)\right.$ & $\left.\Delta \mathrm{G}^{\mathrm{o}}{ }_{\mathrm{n} 1}(\mathrm{kcul} / \mathrm{m}) \mathrm{l}\right)$ & RMSD $(\%)$ \\
\hline 0 & 2.36 & -0.14 & 13.8 & 298.8 & 6.98 & -6.60 & 1.5 \\
2 & 1.77 & -0.11 & 7.91 & 297.8 & 4.22 & -6.99 & 2.8 \\
4 & 3.35 & -0.20 & 21.2 & 296.0 & 2.92 & -7.28 & 0.3 \\
6 & 3.71 & -0.22 & 24.6 & 298.2 & 2.25 & -7.57 & 1.5 \\
8 & 2.88 & -0.17 & 16.7 & 296.1 & 1.98 & -7.58 & 0.3 \\
\hline
\end{tabular}

2005. Fot to. tio. 5 
기는 미셀상에서 닌대이온의 결합상수스ㄱㅏㅏㅏㅄ을 나타내 브로 각 옥도에세 $\beta$ 값이 모누 동일한 것음 반대이옥. 의 결합상수값이 온도의 변화에 따라 크게 변하지 않 음을 의미한다."

$$
\ln C H C A \ln (C H C \mid[K C]) \mid B
$$

Table 1에서 촉정한 ( $\mathrm{MC}$ 값과 $\mathrm{Fg}$. 2에서 구한 $\beta$ 값 $(0.52)$ 을 이용하여 $\wedge \mathrm{G}_{\mathrm{m}}^{\mathrm{m}}$ 값을 식 (1)에 의하여 게 산하였으녀. 그 견과륨 Table 1에 함께 나타내었다. 게 산한 $\triangle \mathrm{G}_{\mathrm{m}}^{\circ}$ 의 값은 온도의 증가에 따라 간소하는: 경 항을 보였으며 또한 $\mathrm{KCl}$ 의 농도롤 증가할수록 역시 감슨하는 경향을 보였다. 이것은 연도가 올라잔수록 그리고 KCI의 농고롤 증가할수록 (PC/XX-100 혼합

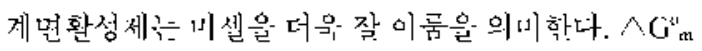
의 값음 $\wedge \mathrm{H}_{\mathrm{m}}^{\prime \prime}$ 와 $\wedge \mathrm{S}_{\mathrm{m}}^{\prime \prime}$ 값의 코기와 부호.에 따라 견 싱되며. 이들 값의 크기와 기여도에 따라 계면활성제 분자의 미셀화 헌상이 엔단피 지배반응 혹은 엔트로 iㅣ 시배반응.으로. 일걸어진다. 계면활성제의 미센화에 대한 $\Delta \mathrm{II}_{\mathrm{m}}^{\circ}$ 값은 식 (1)마 (3)에 의하여 식 (5)와 간이 나타낼 수 있응ㅁㅁ. 그리고 $\triangle \mathrm{S}_{\mathrm{m}}^{\circ}$ 값은 식 (1)파 (5)에 의하여 식 (6)과 같이 나타낸 수 있나. ㄴ.

$$
\begin{aligned}
& \Delta H_{m}^{\prime \prime}=-T^{2}\left[\frac{d\left(\Delta G_{m}^{\prime \prime} T\right)}{d T}\right]_{p}=-(1+\beta) R T^{2}(2 a T-b)(5) \\
& \Delta S_{m}^{o}=\left[\frac{\Delta H_{m}^{o}-\Delta G_{m}^{o}}{T}\right]=-(1+\beta) R\left(3 a T^{2}+2 b T+c\right)(6)
\end{aligned}
$$

죄소자승법으로 구한 $T a b l e$ 2의 번수 $(a b b$ 및 $c)$ 값 과 식 (5)와 (6)을 이욤하여 $\triangle \mathrm{H}^{\prime} \mathrm{m}_{1}$ 와 $\triangle \mathrm{S}_{\mathrm{m}}^{\mathrm{n}}$ 을 각삭 셰 산하었으며. $2 L$ 결과를 Table 3에 나타내었다. $\triangle \mathrm{S}_{\mathrm{m}}^{\mathrm{n}}$ 값은 측정한 떤든 온도에서 양의 값을 나타네었.으며, $\triangle 1 \mathrm{I}_{\mathrm{m}}^{\mathrm{m}}$ 값은 $298 \mathrm{~K}$ 롤 전후로. 하어 양의 값에서 음의 값으로 비퓌었다. 그 결롸 $298 \mathrm{~K}$ 보다 낮은 온-도에서는 $\wedge \mathrm{G}_{\mathrm{m}}^{\mathrm{N}}$ 값이 양의 값을 나타내는 $\wedge \mathrm{H}^{\mathrm{n}} \mathrm{n}_{\mathrm{r}}$ 브나 양의 값인

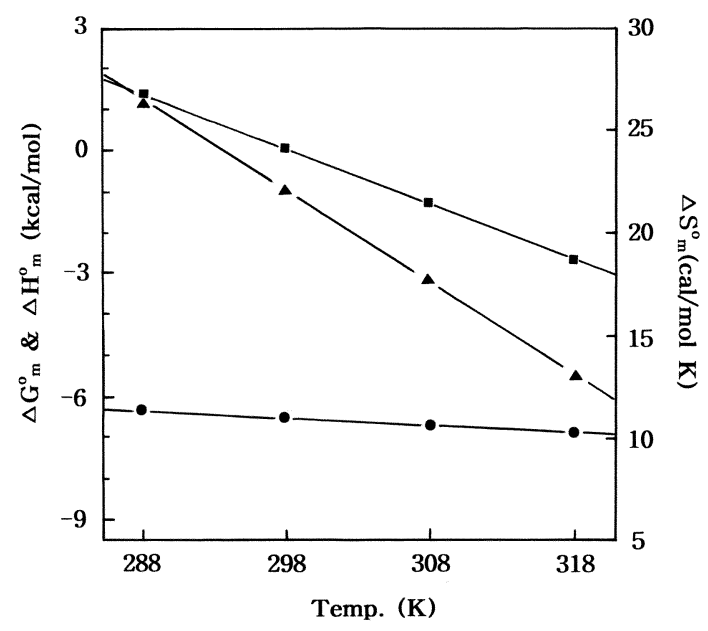

Fig. 3. Plots of thermodynamic parameters versus temperature for the micellization of C.PC.TX-100 mixed surfactant

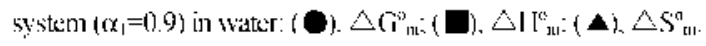

$\triangle \mathrm{S}_{\mathrm{m}}^{\prime \prime}$ 에 의하여 음의 값을 나타내게 되며. $298 \mathrm{~K}$ 보 나 높은 온거에서는 음의 값인 $\Delta \mathrm{Il}_{\mathrm{m}}$ 와 양의 값인 $\Delta \mathrm{S}_{\mathrm{m}}^{\mathrm{o}}$ 가 공농으로 기여함으로써 $\wedge \mathrm{G}^{\prime \prime}$ 의 값이 더욱 콘 은 의 값을 나타네게 된다. Tatble 1가 3에 있는 역역학 핚수값 $\left(\Delta G^{n}{ }_{m+} . \Delta H_{m}^{\circ}\right.$ 및 $\left.\Delta S_{m}^{\circ}\right)$ 들의 온도의존성을 조 사하기 위하어 순수 불에서의 열역학 함수값둔을 온 도에 대하어 Fig. 3에 도시하였다. 여기서 알 수 있듯 이 옴 하는 경향을 보였으며. 모한 이더한 현상이 모돈 $\mathrm{KCl}$ 용액에서도 동일하게 나타났다. Table 3과 Fig. 3에 의 하면 온도의 증가에 마라 엔트로피의 기여도든 섬차 식으로 줄이둔기 오히려 음의 값인 엔탈피의 기어도 가 젂차식으로. 증가하고 있을을 알 수 있다. ${ }^{1 \cdots 21}$ 한젼

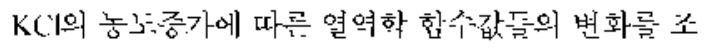
사하기 위하여 $298 \mathrm{~K}$ 에서 열역학 함수값들을 KC이의 듬도에 대하여 도시하여 보있으머. 그 견과률 Fig. 4

\begin{tabular}{|c|c|c|c|c|c|c|c|c|}
\hline \multirow{2}{*}{$\begin{array}{l}\text { Temp. }(K) \\
\text { KClimM) }\end{array}$} & \multicolumn{2}{|c|}{288} & \multicolumn{2}{|c|}{298} & \multicolumn{2}{|c|}{308} & \multicolumn{2}{|c|}{318} \\
\hline & $\Delta \mathrm{I}_{\mathrm{rI}}^{\mathrm{r}}$ & $\Delta S^{\circ}$ & $\triangle \mathrm{II}_{\mathrm{r}}^{\nu}$ & $\triangle S_{\mathrm{II}}^{\mathrm{D}}$ & $\triangle I^{0}{ }_{111}$ & $\triangle S_{\mathrm{\prime \prime}}^{\circ}$ & $\triangle \mathrm{HI}^{\circ}$ & $\Delta S_{\mathrm{rt}}^{\nu}$ \\
\hline 0 & 1.28 & 26.4 & 0.01 & 22.0 & -1.25 & 17.8 & -2.75 & 12.9 \\
\hline 2 & 0.88 & 26.6 & -0.01 & 23.5 & -1.03 & 20.0 & -2.16 & 16.3 \\
\hline 4 & 1.36 & 29.4 & -0.35 & 23.4 & -2.30 & 17.0 & -4.47 & 9.91 \\
\hline 6 & 1.90 & 32.0 & 0.03 & 25.5 & -2.09 & 18.4 & -4.47 & 10.7 \\
\hline 8 & 1.18 & 29.9 & -0.29 & 24.7 & -1.96 & 19.2 & -3.82 & 13.1 \\
\hline
\end{tabular}

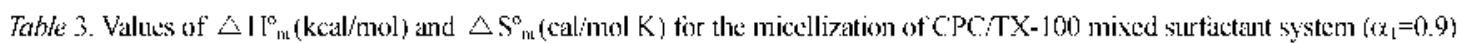
in ikpueous solutions of $\mathrm{KCl}$ al various temperatures 


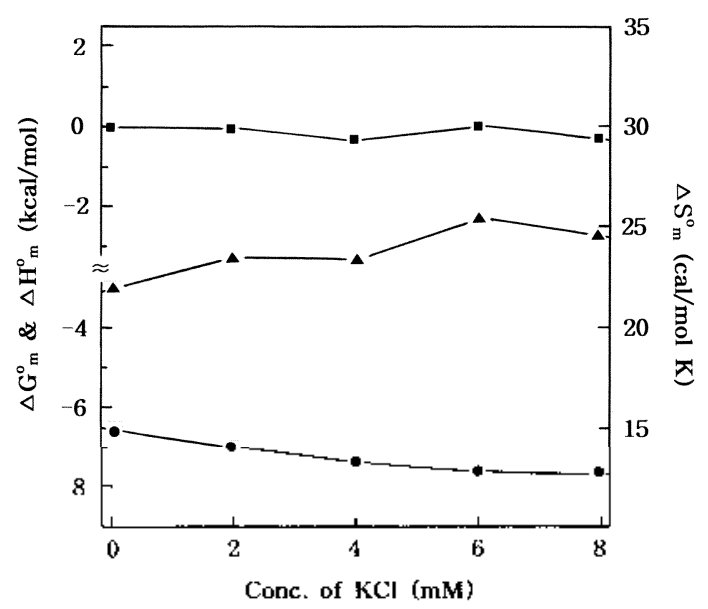

Fig. 4. Plots of themodynamic parameters versus concentration of $\mathrm{KCl}$ for the micellization of (PC/TX-100 mixed

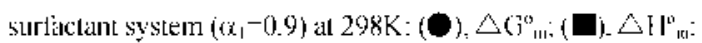
(4). $\triangle S^{\circ}$

에 나타내었나. 여기서 알 수 있듯이 K(이의 농호증가 에 따라 $\Delta\left(\mathrm{i}^{\prime \prime}\right.$ 의 값은 완난하게 갂소하고 있다. 그러

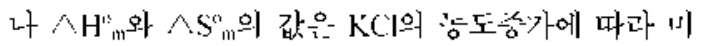
소하쎄 년하고 있은 뿐 일반적인 겅향은 보이지 꼿하 고 있다. 다른 온도에서의 견가도 “영일한 겅항은 보. 이고 있다.

CIYIX-100 혼합계면확성제의 미셀회에 대한 $\triangle \mathrm{H}^{\mathrm{m}}$ 와 $\triangle \mathrm{S}_{\mathrm{m}}^{\mathrm{\prime}}$ 의 삼관성을 조시하끼 위하여 $/ \mathrm{gg}$. 5 에 $\triangle \mathrm{II}_{\mathrm{m}}^{\mathrm{\prime}}$ 을 $\triangle \mathrm{S}_{\mathrm{m}}^{\circ}$ 에 대하여 도시하였다. 그 견과. 모둔 믕도의 $\mathrm{KCl}$ 용액에세 직선을 이루있다. 따라시 $\wedge \mathrm{H}^{\mathrm{n}}{ }_{\mathrm{m}}$ 와 $\wedge \mathrm{S}_{\mathrm{m}}^{\circ}$ 사 이에는 식 (7)과 같이 일차핚수의 식으로 나타낼 수 있으며. $\triangle \mathrm{G}^{0}$ 의 값은 식 (8)과 같이 나다낼 수 있다. 어기서 직선의 기운기 $(p)$ 는 동구조은도-(iko-structural temperature)로서 식 (8)에 의 하면 $\triangle\left(\mathrm{j}_{\mathrm{m}}^{\prime \prime}\right.$ 에 대한 $\triangle \mathrm{S}_{\mathrm{m}}^{\prime \prime}$ 의 기여노가 0 이 되는 옹-3를 나타넨다. ${ }^{+.22}$ 즉 촉정온도(T)가 $p$ 와 같으년 식 (8)의 둘쌔 항은- 0 이 되비. 그 때의 $\triangle \mathrm{G}_{\mathrm{m}}^{\mathrm{m}}$ 값은 $q$ 가 된다. 만약 $\mathrm{T}>\mathrm{p}$ 이년 측싱한 $\Delta \mathrm{S}_{\mathrm{m}}^{\prime}$ 의 값이 양의 값이드로 식 (8)의 둔째 항은 음의 값이 되며. 그 결과 $\triangle \mathrm{G}^{\circ} \mathrm{m}$ 값은 더욱 감손하게 힌다. 그러 나 $\mathrm{T} \&$ 이면, 식 (8)의 눌째 항은 양의 값을 나타내게 되며. 그 결과 $\triangle \mathrm{Ci}_{\mathrm{m}}^{\mathrm{O}}$ 값은 너욱 즘가하게 된다. 이것 을 나른 만호 표현하면 능구조옷도(p) 보다 높은 온 도에서는 $\triangle \mathrm{S}_{\mathrm{m}}^{\mathrm{i}}$ 에 의하여 미셀화가 디욱 춪진되지만. 반대 로 등구조은도 보다 낮은 온도에서는 $\triangle S^{\prime \prime}{ }^{\prime \prime}$ 에 의 하어 미셀화는 되욱 이럽게 됨을 나타낸다.

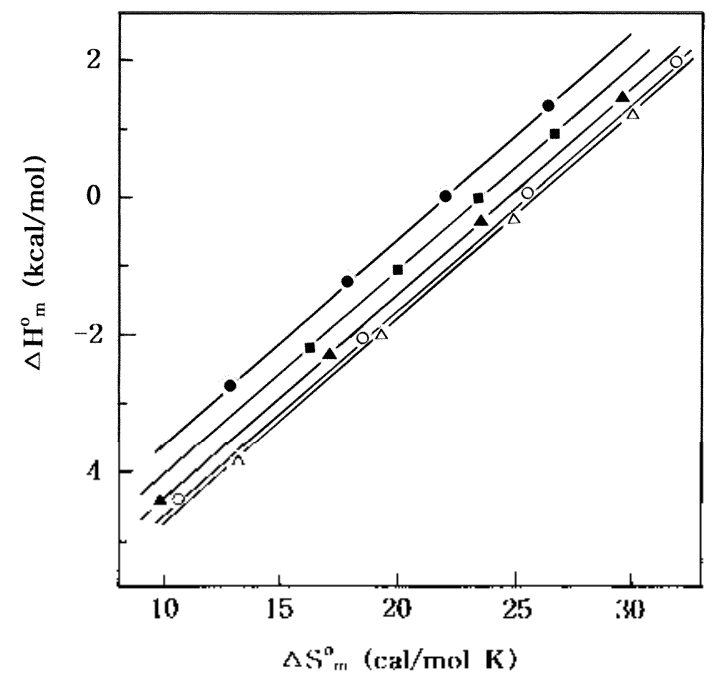

Fig. 5. Plots of $\triangle \mathrm{Hl}^{0}{ }_{11}$ versus $\triangle \mathrm{S}^{\mathrm{v}}{ }_{11}$ for the micellization of (') $\left(\mathrm{C} / \mathrm{TX}-100\right.$ mixed suthatan system $\left(\alpha_{1}-(0.9)\right.$ in appeous solutions of $\mathrm{KCl}$ ( $(\boldsymbol{O})$, no sall: $(\boldsymbol{\square}) .0 .2 \mathrm{M} \mathrm{KCl}:(\boldsymbol{\Delta}) .0 .4 \mathrm{M}$ $\mathrm{KCl}(0), 0.6 \mathrm{M} \mathrm{KCl}$ (스), $0.8 \mathrm{M} \mathrm{KCl}$.

Tethe 4. Derived least square parameters (from equation 7) and root mean square deviation (RMSD) for the micellization of CPCTX-100 mixed surfictant system $\left(c_{1}=0.9\right)$ in aqueous solutions of $\mathrm{KCl}$

\begin{tabular}{|c|c|c|c|}
\hline$\overline{\mathrm{KCl}}(\mathrm{mM})$ & $p(\mathrm{~K})$ & $q(\mathrm{kcal} / \mathrm{mol})$ & RMSD (\%) \\
\hline 0 & 298.8 & -6.59 & 2.87 \\
\hline 2 & 294.9 & -0.95 & 2.31 \\
\hline 4 & 299.8 & -7.42 & 501 \\
\hline 6 & 299.2 & -7.64 & 5.34 \\
\hline 8 & 298.4 & -7.70 & 4.58 \\
\hline \multicolumn{4}{|c|}{$\Delta / f_{m}^{\prime \prime}=p \Delta S_{m,}^{\prime \prime}+q$} \\
\hline
\end{tabular}

Fig. 5에 나타낸 각 지선의 기율-기(p)와 절편 $(q)$ 의 값은 최소사승넙으로 계산하었으며. $=2$ 결과를 Toble 4에 나타네었다. Table 4에서 알 수 있듯이 각 $\mathrm{KCI}$ 용 핵에 대하어 계산한 $p$ 의 값은 $\mathrm{KCl}$ 의 농도에 따라 약 간의 차이를 보이지난 대체적으로 상옹 $(298 \mathrm{~K})$ 근처의 값을 나타내었다. 그리고 $q$ 의 값은 -6.6 에서 $-7.7 \mathrm{kcallin70l}$ 까지 번하헜으버. KC의 응도룩 씅가할수록 $q$ 의 값은전자적으로 감소하는 경향을 보인다. 또한 각 용맥에 서 계산한 의 의 값은 Table 2에 있녹: $\mathrm{T}^{*}$ 에서의 사유에 니지 번회값 $\left(\triangle \mathrm{G}^{+}{ }_{\mathrm{m}}\right)$ 과 거의 동일한 값을 나타네근 있 음을 알 수 있다.

2005. Fot to. tio. 5 


\section{결 론}

CPCTX-100 혼합계면할성제의 미셀화에 대한 $\mathrm{CMC}$ 값은 온도의 증기에 마라 감소하다가 증가하는 경향 을 보였으며 또한 $\mathrm{KCl}$ 의 농도를 증가할수록 $\mathrm{CMC}$ 값 은 계속하여 감소하는 경향을 보였다. 이러한 변화로 부터 계산한 $\triangle \mathrm{G}_{\mathrm{m}}^{\mathrm{\prime}}$ 값은 $-6.33 \mathrm{kcalimol}$ 에 서 $-7.99 \mathrm{kcalimol}$ 까지 변화하였으며. 측정한 모든 범위에서 음의 값을 나타내었다. 또한 $A \mathrm{~S}_{\mathrm{m}}^{\circ}$ 값은 $9.91 \mathrm{cal} / \mathrm{mol} \mathrm{K}$ 에서 32.0 $\mathrm{calimol} \mathrm{K}$ 까지 변화하였으며, 측정한 범위 네에서 도 두 양의 값을 나타네었다. 그러나 $\triangle \mathrm{H}^{\circ}$ 값은 1.90 $\mathrm{kcal} / \mathrm{mol}$ 에서 $-4.47 \mathrm{kcal} / \mathrm{mol}$ 까.지 변하였으며. 측정한 온도에 따라 양 혹은 음의 값을 나타대었나. 온도의 증가에 따라 이늘 열역학 합수값들은 모누 감소하는 경항을 보였다. 그러나 $\mathrm{KCl}$ 의 농도를 증가할수록 $\Delta G_{\mathrm{m}}^{\circ}$

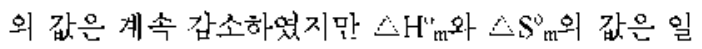
반적인 변화를 보이고 않았다. $\Delta \mathrm{H}^{\circ}$ 을 $\triangle \mathrm{S}^{\circ}$ 에 대하 여 도시한 결과, 직선이 얻어겼으며 그 식선의 기울 기 $(p)$ 로부터 구한 능구조온도는 모누 실온 $(298 \mathrm{~K})$ 근 처의 값을 나타내었나.

\section{인 욤 문 헌}

1. Hlikdebrand, A.: Garidel, P.: Neubert, R.: Blume, A. Langhuir 2004. 20. 320 .

2. Penfold. J.: Tucker, 1.: Thomas, R. K.: Staples. E.: Schuermann, R. J. Phis. Chem. B 2005, 109, 10770.
3. Kim. H. U.: Lee. J. K.: Lim. K. H. J. Korean Ind. Eng. Chem. 2005. 16. 231.

4. Shanma. K. S.: Patil, S. R.: Rakslit. A. K. J. Phys. Chem. B 2004. 108, 12804.

5. Lee. B. H. J. Kor: Chem. Soc. 1994, 38, 539.

6. Muller, ․, Langmir 1993, 9, 96.

7. Mesa C. La J. Phrs. Chem. 1990, 94, 323.

8. Bertancini, C. R, A.: Neves, M. de F.: Nome, F. Langmir 1993, 9, 1274.

9. Junquera, E.: Aicart. E. Langmir 2002, 18,9250.

10. Burgo, P. del: Junquera, E.: Aicart, E. Langmir 2004, 20. 1587.

11. Bastiat, G: Gras, B.: Khoukh, A.: Francois, J. Langmir 2004, 20,5759.

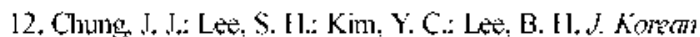
Ind d Eng. Chem. 1998, 9, 968.

13. Kim, Y. C. In Ph. D. dissertation: Kyung-Pook National Liniversity. 1997; 22.

14. Slanks. P. C.: Franses. E. I. J. Phrs. Chem 1992, 96, 1794.

15. Zana, R.: Lery, H1.: Papoutsi, D.: Bẹmert. G Langmir $1995,11,3694$.

16. Paula S.: Sus, W.: Tuchtenhagen, J.: Blume, A. J. Phys. Chem. 1995. 99. 11742.

17. Burrows. J. C.: Flynn, I.: Kutay. S. M.: Leriche, T. Ci: Marangoni, D. G. Longmuir 1995. //, 3388.

18. Shinoda. K. Bull. Chen. Soc. Jpn. 1963. 26. 101.

19. Douglas. C. B.; Kaler, E. W. Langmir 1994. $10,1075$.

20. Garamus. V. M. Langmuit 2003. 19. 7214.

21. Lusvardi. K. M.: Full, A. P.: Kalen, E. W. Longhuir 1995, /l. 487.

22. Lee. B. H. J. Kor Chen. Soc: 1993. 37.562 